ageing process of women's sexuality.

Some women seem to ignore the symptoms of the climacteric. Greer argues that this has more to do with their coping style than the extent to which they experience symptoms. Many older women find satisfaction where men do - in their relations with their employer, and in the feeling of well-being that comes from mastering their job. Greer muses wistfully on how much better women would feel during the menopause if, instead of losing prestige, power and responsibility, they were to gain all three, as they do in matrilocal societies of the so-called developing countries.

Greer defends the right of women in their 50 s to their mood-swings. After the years of silent rage endured as the family's doormat, many women suddenly find that they are poor, dependent, insecure and lonely, and they should not have to feel guilty about their justified moodiness as well; by contrast, the husband usually has the social continuity of his career to sustain him and is supported by a society that finds older men more attractive than women of the same age. In particular, women should be allowed to grieve when "the day has passed its noon and the shadows are growing ever shorter and bleaker"; and she tells us that they must demand their own space so that they may make the final part of their lives as rewarding as possible. She encourages them to redefine their image and develop reasonable expectations about the climacteric.

The book contains a perceptive examination of historical and fictional stereotypes of ageing women. And as a final bonus, there is a charming chapter in which we are treated to the poetry and biographical details of some of the great women survivors. Karen Blixen was 46 when she returned from Africa to her native Denmark with spinal syphilis and a life in turmoil. To aid her recovery, she fashioned herself as a writer under the name of Isak Dinesen: Out of Africa was to be her masterpiece, but in an earlier book she describes a woman that could as well have been herself or even the author of The Change:

What changed her was what changes all women at fifty; the transfer from the active service of life - with a pension or the honours of war, as the case may be to the mere passive state of a looker on. A weight fell away from her; she flew up to a higher perch and cackled a little.

Greer's hope that all women will one day gain prestige at the time of the climacteric is unrealizable. But on reading this informative book they will at least know that they are not alone.

Olivia Cox-Fill is at 19 Cheyne Walk, London SW3 5RA, UK.

\section{Making bucks}

\section{Thomas W. Ebbesen}

How to Profit from Fullerenes: Winning Strategies for Emerging Markets. Technical Insights: 1992. Pp. 165. \$1,225 (\$1,275 outside North America). (For further information, contact $P$. Finlay, Technical Insights, PO Box 1304, Fort Lee, New Jersey 07024-9967, USA.)

WHEN experimental evidence for the existence of fullerenes $\left(C_{60}\right.$ and $\left.C_{70}\right)$ was reported in 1985 (H. W. Kroto et al., Nature 318, 162; 1985), it sparked the imagination of scientists worldwide. If fullerenes really existed, they would form a unique new class of material the first all-carbon molecules, spherical, hollow, aromatic and highly symmetric. So unique properties were expected, but there was no way to find out, because only trace amounts of the material were present in the mass spectrometer. Theoreticians got to work and predicted, among other things, the simple fourpeak infrared absorption spectrum of $\mathrm{C}_{60}$. The breakthrough came in 1991, when W. Kratschmer and D. R. Huffman noticed the same spectrum for the soot they had generated in carbon-arc experiments, from which they eventually extracted $\mathrm{C}_{60}$ (D. R. Huffman, Physics Today, November 22-29; 1991).

This simple experiment finally made fullerenes available to everyone, in milligram to gram quantities. It resulted in an explosion of research activity, from organic chemistry to solid-state physics. Within a year, the prediction that $\mathrm{C}_{60}$ was a unique new material was confirmed, most spectacularly perhaps by the discovery of its superconductivity at AT\&T Bell Laboratories.

So in this context of excitement and broad interest, it is not surprising that there is a market for a book on the potential of fullerenes in the marketplace. Indeed, a lot of companies have invested in fullerene research and others are considering following suit. How to Profit from Fullerenes is stimulating and should provide a useful overview for business people. It points out, probably correctly, where the market potential of fullerenes is to be found; but sadly it is spoiled by many scientific, and sometimes historical, inaccuracies.

The book starts with an "executive summary" of the contents, which indeed should be useful enough for busy administrators. But it is not always consistent with the later chapters. This is of course a problem in a rapidly evolving field where breakthroughs are made monthly. For instance, carbon nanotubes (alias buckytubes) are described first in terms of whether or not they exist and then in terms of their availability in usable quantities. At the end of the book their large-scale synthesis is reported.

Busy readers should also take the time to look through the first two chapters, which give a good short perspective on fullerenes. I would agree with the statement that collaborative research is probably the most effective path to take because, with the rapid pace of development in fullerene research, "no single group can take full advantage of every salient discovery". That has been clearly observed. It also seems true that fullerenes are not just a fad but a durable and expanding field, especially with the prospects for 'customized', chemically modified fullerenes.

Chapter 3, "Properties, Synthesis and Purification", gives an introduction to the chemical kinetics and has far too much detail for nonscientists, but is insufficient and too inaccurate for scientists. Chapter 4 discusses chemically modified fullerenes in the broadest sense and is useful for nonspecialists. Here it is again argued convincingly that chemical modification of fullerenes into a hightech material has the greatest potential, giving them enough added value to cover the high cost of raw fullerene material. (At about a billion dollars a ton, it is certainly unlikely that $\mathrm{C}_{60}$ will compete in, say, the rocket fuel market, as some have suggested.)

In Chapter 5, potential applications markets in which fullerenes would compete are discussed. Areas such as superconductivity, nonlinear optics, diamond making and chromatography are covered. Perhaps the most intriguing story is the invention of rhondite, an ironfullerene blend analogue of steel which under the proper heat treatment turns fullerene carbon into diamond, resulting in so-called 'diastcel'. The least explored territory is the use of fullerene-based materials in pharmaceutics and medicine (for example in immunoassays). The report ends with a very partial listing of researchers worldwide involved in fullerene development projects.

The US Patent Office apparently now receives more correspondence on fullerenes than on all other inventions combined. Although their true potential remains unknown, there is no question that fullerene-based materials will provide opportunities not to be missed.

Thomas W. Ebbesen is in the Fundamental Research Laboratories, NEC Corporation, 34 Miyukigaoka, Tsukuba 305, Japan.

Newly published is Macmillan's Chemical and Physical Data by A. M. James and M. P. Lord, a rich and concise source of fundamental data in 17 well-defined subject areas, from atomic and nuclear physics to acoustics. Macmillan, £35.

NATURE - VOL 361 . 21 JANUARY 1993 